\title{
Correction: Multi-ancestry fine mapping of interferon lambda and the outcome of acute hepatitis $\mathrm{C}$ virus infection
}

Candelaria Vergara (1) - Priya Duggal - Chloe L. Thio - Ana Valencia - Thomas R. O'Brien - Rachel Latanich • Winston Timp - Eric O. Johnson - Alex H. Kral • Alessandra Mangia - James J. Goedert • Valeria Piazzola • Shruti H. Mehta · Gregory D. Kirk • Marion G. Peters · Sharyne M. Donfield • Brian R. Edlin • Michael P. Busch (1) • Graeme Alexander · Edward L. Murphy · Arthur Y. Kim • Georg M. Lauer (D) Raymond T. Chung • Matthew E. Cramp - Andrea L. Cox · Salim I. Khakoo - Hugo R. Rosen · Laurent Alric - Sarah J. Wheelan · Genevieve L. Wojcik $($ D David L. Thomas - Margaret A. Taub

Published online: 23 November 2020

(c) The Author(s), under exclusive licence to Springer Nature Limited 2020

Correction to: Genes \& Immunity

https://doi.org/10.1038/s41435-020-00115-3

The original version of this article contained an error in the author name for Thomas R. O'Brien. The family name contained a space and incorrectly appeared as O' Brien. This has now been corrected in both the PDF and HTML versions of the article. 